\title{
Prevalence of Pregnancy in Drug Overdose Presenting to a Tertiary Toxicology Service
}

\author{
Mark Daniel Salter ${ }^{1-4}$, Pramod Chandru ${ }^{1-4}$, Kit Rowe ${ }^{1,2,4}$, Phillip Smith ${ }^{1,4}$, Naren Gunja ${ }^{1,2,4}$ \\ 'Western Sydney Toxicology Service, Westmead and Blacktown Hospitals, Westmead, NSW, Australia; ${ }^{2}$ Faculty of Medicine, University of Sydney, \\ Sydney, NSW, Australia; ${ }^{3}$ Department of Emergency Medicine, Nepean Hospital, Kingswood, NSW, Australia; ${ }^{4}$ Department of Emergency Medicine, \\ Westmead Hospital, Westmead, NSW, Australia
}

Correspondence: Mark Daniel Salter, Tel +6I 2 47342763, Email mark.salter@health.nsw.gov.au

Introduction: Poisoning in pregnant women creates challenges to healthcare providers due to the potential for dual harm to the mother and fetus from the exposure. The unknown safety profile of antidotes in pregnancy and nature of supportive care for pregnant women further complicate this presentation. Within the ED, the prevalence of unexpected pregnancy is shown to be between 0.2 and $6.3 \%$ for all presentations, whilst studies specific to poisonings demonstrate a prevalence of $0.07-0.6 \%$.

Materials and Methods: The Western Sydney Toxicology Service (WSTS) works in the Western Sydney Local Health District to provide specialist poisons care to patients. We conducted a retrospective cohort study of all women who presented to the ED in Western Sydney hospitals requiring specialist toxicology advice or admission between ages 14 and 50 years. Primary outcome was the rate of pregnancy, especially unexpected pregnancy, between Jan 2013 and Nov 2019. Secondary outcomes included determining compliance with department policy of blood $\beta$-HCG testing for all female patients in reproductive years, rates of polypharmacy ingestions, types of exposures and drug classes commonly associated with poisoning.

Results: Overall: The pregnancy rate was $1.6 \%(\mathrm{n}=39)$, while the unexpected pregnancy rate was $0.78 \%(\mathrm{n}=19)$. About $99.3 \%(\mathrm{n}=$ 2421) had a blood test taken in ED or day one of admission, with $65.8 \%(\mathrm{n}=1605)$ having a blood $\beta$-HCG level measured. There was a higher proportion of deliberate self-poisonings $(72.6 \%, \mathrm{n}=1771)$ compared to other exposures. Single drug exposures occurred in $58.9 \%(n=1436)$. There was a mean of 1.56 drug class exposures per patient $(n=3795)$, with paracetamol being the most common $(26.9 \%, \mathrm{n}=656)$.

Discussion and Conclusion: There was a low rate of pregnancy, especially unexpected pregnancy, in keeping with studies in the poisoned population. We noted moderate compliance with our department policy of blood $\beta$-HCG measurement and determined that most exposures were deliberate self-poisonings, with over a quarter involving paracetamol.

Keywords: drug overdose, poisoning, pregnancy, toxicology

\section{Plain Language Summary}

This study was completed to determine the proportion of pregnancy in the female population who are in their reproductive years and present with poisoning to the Emergency Department. This presentation clearly has challenges for the clinicians tasked with patient care, due to the poisoning effects on the mother and the fetus. There are concerns surrounding supportive management, use of antidotes which may affect the fetus, and the drug effects on the fetus in the different stages of pregnancy. In the Western Sydney Toxicology Service, we developed a policy of blood $\beta$-HCG testing as the gold standard of determining pregnancy in reproductive years to ensure that no pregnancy was missed to assist us in tailoring care and providing follow-up.

Our study demonstrated an unexpected pregnancy rate similar to other studies on the overall ED population and in the poisoned patient. We had moderate compliance in following the department policy but this may have been due to urine $\beta$-HCG being tested prior to a blood test being collected or other factors which may have been explored which would have made pregnancy extremely unlikely. We did not explore these outcomes in the study and it is an obvious limitation.

We also found that almost three quarters of the presentations were patients taking drug overdoses (deliberate self-poisonings) whilst almost 6 in 10 poisonings were with single agents. Importantly, paracetamol, a common over-the-counter pain and fever reliever, was found to be the most commonly used drug for most groups analyzed in the study. 


\section{Introduction}

Poisoning has been previously shown to be the third leading cause of injury-related hospitalization in the United States, accounting for $16 \%$ in one study but at a lower rate ratio among women aged $15-19$ years. ${ }^{1}$ Poisoning in pregnant women creates unique and difficult challenges to healthcare providers due to the potential for dual harm from the exposure to the mother and fetus. Fetal harm may occur through significant distress from the exposure, potential teratogenicity, fetal demise or from the effects of antidotes. ${ }^{2}$ Older studies have shown that poisoning in pregnancy can lead to increased rates of miscarriage and potential teratogenic complications. One recent study found that the proportion of miscarriage almost doubled, though there was no increased risk of premature birth or congenital abnormalities. ${ }^{3}$ Multiple studies have since demonstrated that acute poisonings do not lead to congenital abnormalities. If they occur, the abnormality rates are similar to sibling or baseline prevalence, birth weight and cognitive status were not affected and the poisoning event occurred outside of the high risk gestational period of 4-12 weeks. ${ }^{4-8}$ In contrast, a recent study of intentional poisonings found increased adverse outcomes, including premature birth $(\mathrm{OR}=1.34)$, low birth weight $(\mathrm{OR}=1.49)$ and circulatory system congenital anomalies $(\mathrm{OR}=2.17) .{ }^{9}$ It is rare that poisoning leads to maternal death, with most studies having a maternal death rate of below $1 \%{ }^{10-12}$

The prevalence of unexpected pregnancy in the Emergency Department (ED) is between $0.2 \%$ and $6.3 \%$ in different populations who present for causes which require knowledge of pregnancy status such as trauma, pulmonary embolus, the exclusion of ectopic pregnancy, or who require the use of ionizing radiation. ${ }^{13-16}$ The prevalence of known pregnancy in poisoned patients from two large studies was found to be $0.07-0.6 \%$ of all cases reported, which is less than the total ED prevalence. ${ }^{17,18}$

Pregnancies with advanced gestation had a significantly lower proportion of suicide attempts, with the danger period typically being the first month after conception and $61 \%$ occurring within the first 2 months of gestational life. ${ }^{19}$ The prevalence of unexpected pregnancy in poisoned patients at the time of presentation to ED is not well characterized, with no known Australian studies at present. In one prospective study found, it was shown to be $11.6 \%$ in women 12-30 years of age in 371 patients. ${ }^{11}$ The outcomes for these patients were a level of toxicity at or below minimal toxicity in $81 \%$ of pregnant patients and all had complete recovery. Given the paucity of evidence, this group remains a potential risk for complications including miscarriage and congenital abnormalities if pregnancy status is not determined at ED presentation.

The measurement of beta-Human Chorionic Gonadotropin ( $\beta-\mathrm{HCG})$ in blood for all female patients of child bearing age that present with poisoning has been a long-standing practice in our district health service. The four EDs in our district all routinely order $\beta$-HCG and refer these patients to the regional toxicology service. The policy was instituted over 25 years ago, given the small potential for false-negative results on urine $\beta$-HCG analysis, and is considered gold standard for pregnancy testing for toxicology patients. ${ }^{20-23}$ This study aimed to determine the rate of unexpected pregnancy in this high-risk cohort and compliance to the policy in place.

\section{Materials and Methods}

\section{Study Setting}

The Western Sydney Toxicology Service provides specialist consultation and management in poisoned patients to a region of Australia comprising nearly 1.5 million people. This district is served by four EDs with a combined presentation number of over 200,000 patients annually. The toxicology database contains demographic and poisoning data for all patients referred to the service. The study was approved by the district Human Research and Ethics Committee.

\section{Study Design}

We conducted a retrospective study of ED referrals of all female patients with the potential for pregnancy to our service between January 2013 and November 2019. Females with the potential for pregnancy were defined by age, and included those aged over 14 years to those below 50 years of age. A search of those aged 10-14 and 50-60 years identified no positive pregnancies. The case mix included those with deliberate self-poisoning (DSP), therapeutic misadventure (TM), 
accidental ingestions and recreational drug use. We excluded patients who did not meet age criteria, who were referred from inpatient ward admissions, and those with non-drug overdose presentations, such as envenomation.

\section{Study Outcomes}

The primary outcome for the study was measuring the prevalence of unexpected pregnancy between 14 and 50 years of age who are referred to our service with drug overdose. The secondary outcome measures included compliance rates of staff in performing $\beta$-HCG test for all poisoned women, a comparison of rates of polypharmacy and drug classes identified in poisoning for all included patients and subsequently in those not pregnant, those with pre-existing pregnancy and those with unexpected pregnancy.

\section{Data Collection and Analysis}

Data was collected and collated from the service database for all ED referred patients from January 2013-November 2019 by two independent researchers with good agreement for the patients presenting in 2016. Data collection from the electronic medical record (Cerner Millennium, Kansas City, MO, USA) was transposed to a study spreadsheet, including demographics, blood $\beta$-HCG level, prior knowledge of pregnancy status, the rate of polypharmacy overdose compared to single ingestion, intoxicant and type of exposure. Descriptive statistics were used to report proportions among groups, with frequencies and percentages for categorical variables and means (median, interquartile range, 95\% CI) for continuous variables.

\section{Results}

A total of 6595 patients were referred to our department from January 2013 to November 2019. Of those, 50\% ( $\mathrm{n}=3299)$ were female. The mean age of all included patients was 28.9 years (27, IQR 20-37, 95\% CI 28.5-29.3 years). (Table 1) Inclusion criteria was met by $73.9 \%(\mathrm{n}=2438)$, while $22.7 \%(\mathrm{n}=750)$ were excluded due to being outside the inclusion age range and $3.4 \%(\mathrm{n}=111)$ due to inadequate documentation (Figure 1). Of the included 2438 patients, $99.3 \%(\mathrm{n}=$ 2421) had a blood test completed in ED or within the first 24 hours of admission but only $65.8 \%(n=1605)$ had a blood $\beta$-HCG level measured to comply with the departmental policy.

There was a higher proportion of DSP $(72.6 \%, \mathrm{n}=1771)$ compared to recreational $(15.0 \%, \mathrm{n}=365), \mathrm{TM}(7.9 \%, \mathrm{n}=$ $192)$ and accidental $(4.5 \%, \mathrm{n}=110)$. Single drug exposures occurred in $58.9 \%(\mathrm{n}=1436)$ compared to $41.1 \%(\mathrm{n}=1002)$ polypharmacy exposures. There were 1.56 drug class exposures per patient $(\mathrm{n}=3795)$. (Figure 2) Paracetamol exposures were the most common $(26.9 \%, \mathrm{n}=656)$ whilst clonidine was the most infrequently used $(1.0 \%, \mathrm{n}=24)$.

There were 39 pregnancies (1.6\%), with 34 having $\beta$-HCG levels measured and 5 noting pre-existing pregnancies or recent measured levels. The proportion of unexpected and pre-existing pregnancies was $0.78 \%(\mathrm{n}=19)$ and $0.82 \%(\mathrm{n}=$ 20). Mean age was 30.8 years (29, IQR 22-39 years, 95\% CI 27.6-33.9 years). The type of exposure again showed a higher proportion of DSP $(71.8 \%, \mathrm{n}=28)$ when compared to other forms of poisoning (Table 1). There were similar single drug exposures $(48.7 \%, \mathrm{n}=19)$ when compared to polypharmacy exposures $(51.3 \%, \mathrm{n}=20)$. There were 1.54 drug class exposures per patient $(\mathrm{n}=60)$ and the percentage used per patient shown in Figure 3. Paracetamol exposures were again most common $(38.5 \%, \mathrm{n}=15)$.

There were 2399 patients who were not pregnant in the study. Mean age for this group was 28.89 years (27, IQR 2037 years, 95\% CI 28.5-29.3 years). DSP was again the most frequent type of ingestion $(72.7 \%, \mathrm{n}=1743)$ with recreational the next most likely $(15 \%, \mathrm{n}=361)$. (Table 1$)$ Single drug exposures occurred substantially more $(59.1 \%$, $\mathrm{n}=1417)$ than polypharmacy exposures $(40.9 \%, \mathrm{n}=982)$. There were 1.56 drug class exposures per patient $(\mathrm{n}=3731)$. Paracetamol exposures were the most common $(26.7 \%, \mathrm{n}=641)$ whilst clonidine again was the most infrequently used $(1.0 \%, \mathrm{n}=24)$.

For those patients with a pre-existing and unexpected pregnancy, the mean ages were 26.9 years (26.5, IQR 22-31 years, 95\% CI 23.9-29.9 years) and 34.9 years (39, 28-45 years, 95\% CI 29.5-40.3 years), respectively. Again, there was a higher proportion of DSP exposures $(65.0 \%, \mathrm{n}=13 \mathrm{v} 79.0 \%, \mathrm{n}=15)$ when compared to the other forms of poisoning in both groups (Table 1). There were less single drug exposures in the pre-existing pregnancy group when compared to the unexpected pregnancy group. Drug class exposures were similar whilst in the pre-existing pregnancy group, paracetamol 
Table I Descriptive Analysis of Age, Exposure Type, Number of Agents Used per Patient and Number of Drug Classes

\begin{tabular}{|c|c|c|c|c|c|}
\hline Variable & $\begin{array}{l}\text { Total Patients } \\
\qquad(n=2438)\end{array}$ & $\begin{array}{l}\text { All Pregnancies } \\
\qquad(n=39)\end{array}$ & $\begin{array}{c}\text { Pre-Existing } \\
\text { Pregnancy }(n=20)\end{array}$ & $\begin{array}{c}\text { Unexpected } \\
\text { Pregnancy }(n=19)\end{array}$ & $\begin{array}{l}\text { Not Pregnant } \\
\quad(n=2399)\end{array}$ \\
\hline Mean Age (median; IQR) & $\begin{array}{l}28.9 \text { years } \\
(27 ; 20-37 \text { years })\end{array}$ & $\begin{array}{l}30.8 \text { years } \\
(29 ; 22-39 \text { years })\end{array}$ & $\begin{array}{l}26.9 \text { years } \\
(26.5 ; 22-31 \text { years })\end{array}$ & $\begin{array}{l}34.9 \text { years } \\
(39 ; 28-45 \text { years })\end{array}$ & $\begin{array}{l}28.9 \text { years } \\
(27,20-37)\end{array}$ \\
\hline \multicolumn{6}{|l|}{ Type of Exposure } \\
\hline Deliberate Self-Poisoning & $72.6 \%(177 I)$ & $71.8 \%(28)$ & $65.0 \%(13)$ & $79.0 \%(15)$ & $72.7 \%(1743)$ \\
\hline Therapeutic Misadventure & $7.9 \%(192)$ & $10.3 \%(4)$ & $10.0 \%(2)$ & $10.0 \%(2)$ & $7.8 \%(188)$ \\
\hline Recreational & $15.0 \%(365)$ & $10.3 \%(4)$ & $10.0 \%(2)$ & $10.0 \%(2)$ & $15 \%(361)$ \\
\hline Accidental & $4.5 \%(110)$ & $7.7 \%(3)$ & $15.0 \%(3)$ & $0 \%(0)$ & $4.5 \%(107)$ \\
\hline \multicolumn{6}{|l|}{ Number of Agents } \\
\hline Single Agent & $58.9 \%(1436)$ & $48.7 \%(19)$ & $40 \%(8)$ & $57.9 \%(\mathrm{II})$ & $59.1 \%(1417)$ \\
\hline Polypharmacy & $41.1 \%(1002)$ & $51.3 \%(20)$ & $60 \%(12)$ & $42.1 \%(8)$ & $40.9 \%(982)$ \\
\hline \multicolumn{6}{|l|}{ Drug Classes } \\
\hline Paracetamol & $26.9 \%(656)$ & $38.5 \%(15)$ & $31.4 \%(11)$ & $21.1 \%(4)$ & $26.7 \%(64 I)$ \\
\hline Sedative-Hypnotics & $17.2 \%(4 \mid 9)$ & $15.4 \%(6)$ & $11.3 \%(4)$ & $10.5 \%(2)$ & $17.2 \%(4 \mid 3)$ \\
\hline Opiates & $14.2 \%(347)$ & $23.1 \%(9)$ & $14.3 \%(5)$ & $21.1 \%(4)$ & $14.1 \%(338)$ \\
\hline NSAIDs & $8.1 \%(197)$ & $7.7 \%(3)$ & $5.7 \%(2)$ & $5.3 \%(1)$ & $8.1 \%(194)$ \\
\hline Antihistamines & $6.6 \%(160)$ & $0 \%(0)$ & $0 \%(0)$ & $0 \%(0)$ & $6.7 \%(160)$ \\
\hline Antidepressants & $18 \%(438)$ & $12.8 \%(5)$ & $2.9 \%(I)$ & $21.1 \%(4)$ & $18 \%(433)$ \\
\hline Antipsychotics & $14.4 \%(350)$ & $15.4 \%(6)$ & $2.9 \%(I)$ & $26.5 \%(5)$ & $14.3 \%(344)$ \\
\hline Alcohol & $10.5 \%(257)$ & $2.6 \%(I)$ & $2.9 \%(I)$ & $0 \%(0)$ & $10.7 \%(256)$ \\
\hline Stimulants & $3 \%(72)$ & $2.6 \%(I)$ & $0 \%(0)$ & $5.3 \%(I)$ & $3 \%$ 97I) \\
\hline Anticonvulsant & $3.4 \%(83)$ & $2.6 \%(I)$ & $2.9 \%(I)$ & $0 \%(0)$ & $3.4 \%(82)$ \\
\hline Mood Stabiliser & $2.4 \%(59)$ & $2.6 \%(I)$ & $0 \%(0)$ & $5.3 \%(I)$ & $2.4 \%(58)$ \\
\hline Antihypertensive & $1.2 \%(30)$ & $0 \%(0)$ & $0 \%(0)$ & $0 \%(0)$ & $1.3 \%(30)$ \\
\hline
\end{tabular}


Total patients to WSLHD Toxicology Service January 2013 to November 2019

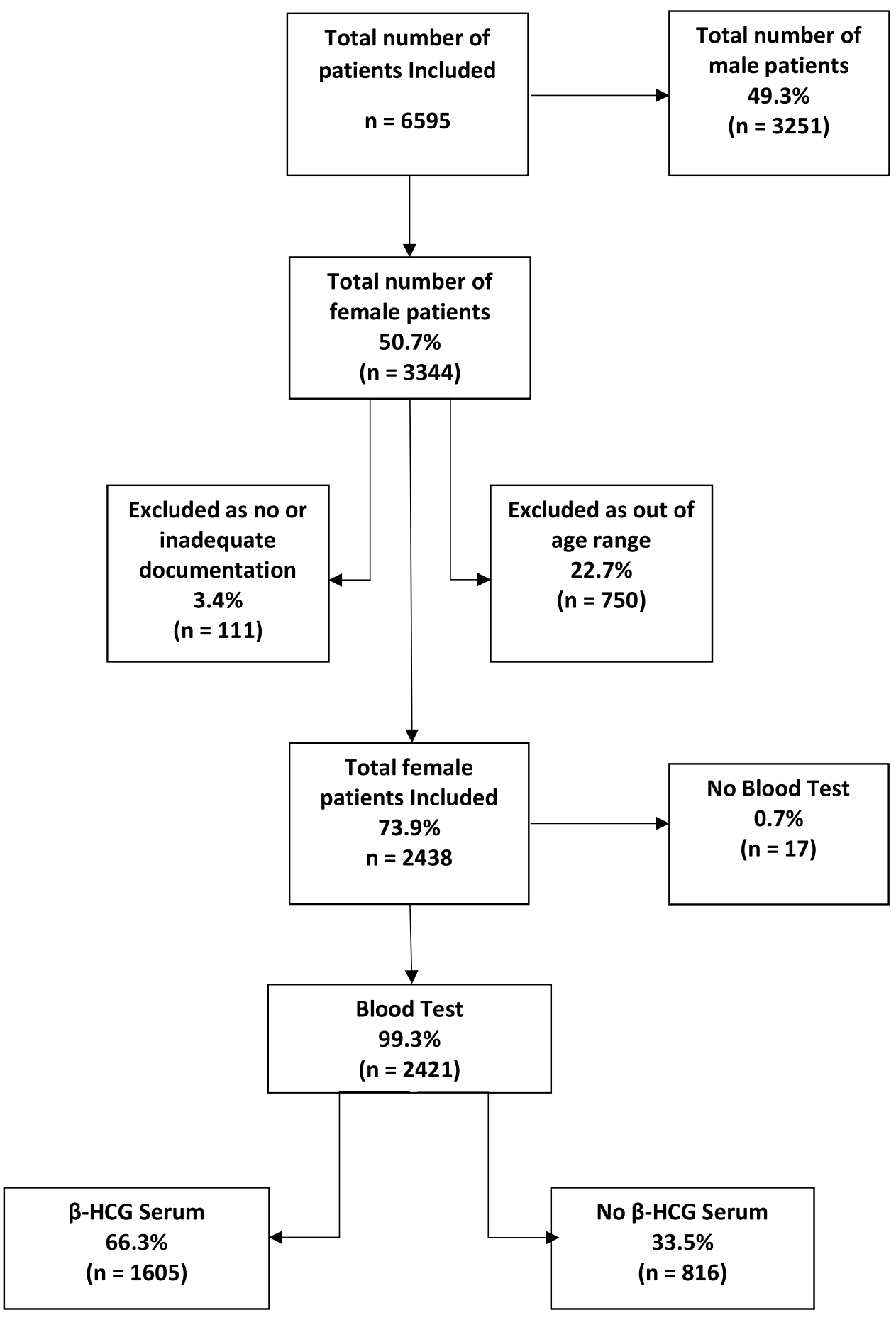

Figure I Patient selection. 


\section{Drug classes of the study population}

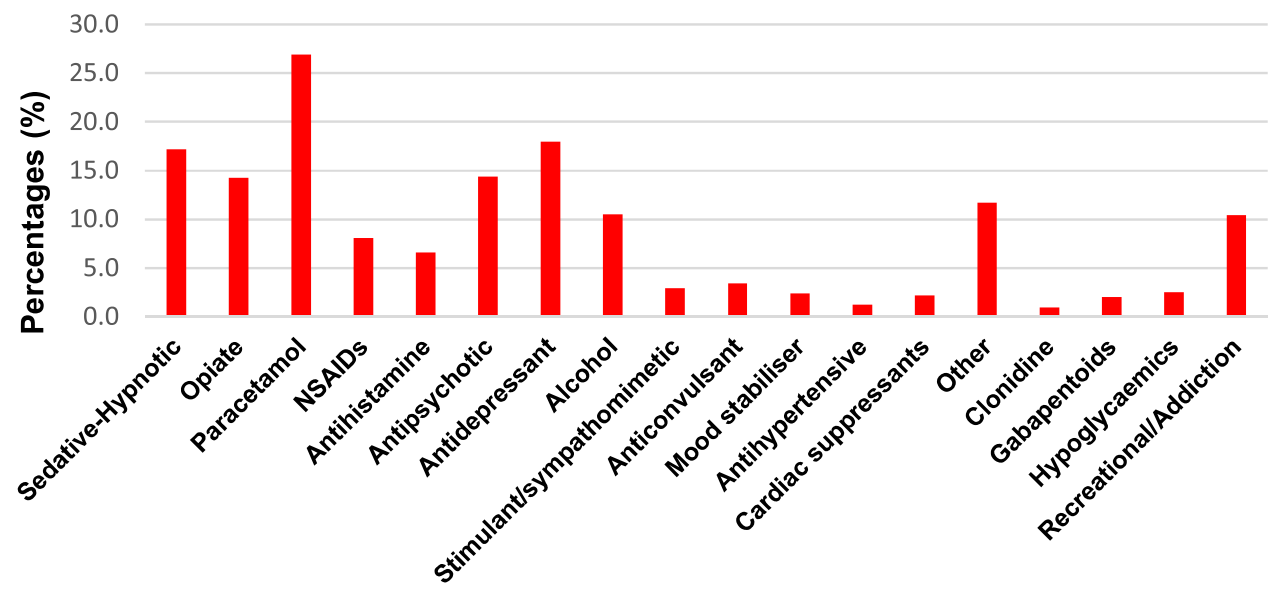

Drug Classes

Figure 2 Percentage of drug classes used by the patients in the study $(n=2438)$.

\section{Drug classes in sub-groups}

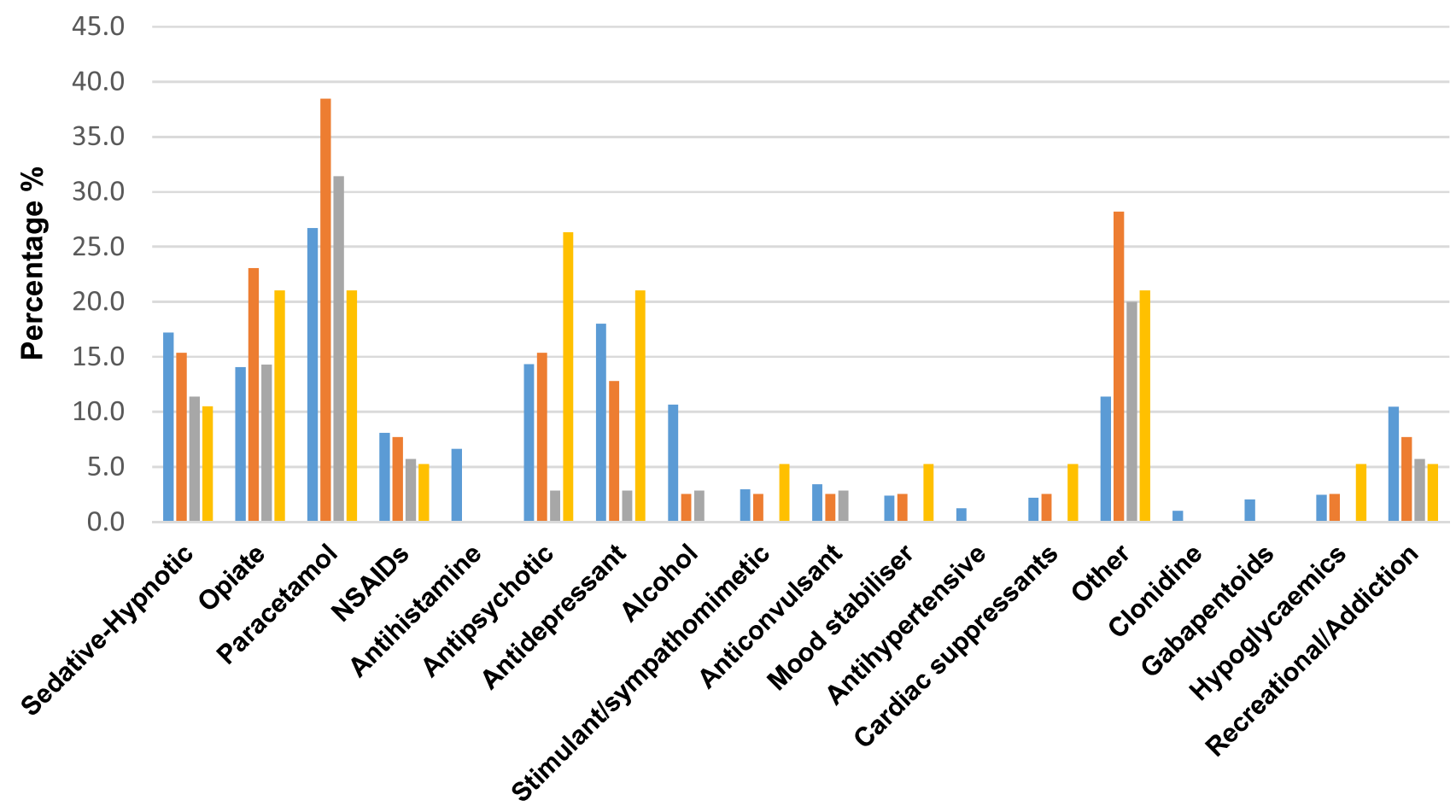

Non-pregnant $\quad$ All pregnancies $\square$ Pre-existing pregnancy $\square$ Unexpected pregnancy

Figure 3 Comparison of the percentage of drug exposures including total number of pregnant patients, pre-existing pregnancy and unexpected pregnancy.

exposures were again most common $(31.4 \%, \mathrm{n}=11)$, whilst antipsychotics were the most common used class $(26.5 \%$, $\mathrm{n}=5$ ) in unexpected pregnancies.

Age comparison of pregnancy status of included women demonstrated a trend towards higher ages in known pregnancy, with a mean age of 28.9 years for non-pregnant patients. This is compared to 30.8 years for those pregnant. 
There was also a trend within the pregnancy group, with pre-existing pregnancy patients being younger in comparison to those with unexpected pregnancy (26.9 years $\mathrm{v} 34.9$ years).

The type of exposure also demonstrates a predisposition towards DSP across all patients, non-pregnant patients and pregnant patients $(72.6 \% \mathrm{v} 72.7 \% \mathrm{v} 71.8 \%)$. In those patients that were pregnant, a higher proportion of unexpected pregnancies had a DSP when compared to pre-existing pregnancies (79\% v 65\%). Single agent ingestions were noted to be larger in proportion than polypharmacy in all patients (58.9\%), those who were not pregnant (59.1\%) and those who had an unexpected pregnancy (57.9\%) when compared to those who were pregnant (48.7\%) and had a known pregnancy $(40 \%)$.

Paracetamol was consistently demonstrated to be the most significant drug class that patients were exposed to and were consistent across all classes. Sedative-hypnotics, opiates, antidepressants and antipsychotics also demonstrated similar proportions when compared across all groups, as demonstrated in Table 1.

\section{Discussion}

The discovery of unexpected pregnancy in the ED is a rare phenomenon that occurs in a small percentage of women. Our study demonstrated a rate of pregnancy in patients who present with poisoning that was consistent with the narrow range presented in previous studies, except for Perrone et al who found a rate significantly higher than others at $11.6 \%$. ${ }^{11,13,16-18}$ The knowledge of pregnancy however may be vital in these women. The poisoned pregnant patient presents significant challenges at the time of presentation with regard to toxic effects of the poisoning for the mother and fetus. It is also challenging over time, with the possibility of some teratogenic effects of the poisoning itself and the increased potential for miscarriage, which may in fact double with exposure. ${ }^{3}$

Our toxicology service has a long-standing policy of blood $\beta$-HCG testing in all females of childbearing age presenting with DSP to mitigate the risk of adverse consequences for the patient and fetus. The results of this study suggest that this has a low yield, with $1.6 \%$ of female patients confirmed as pregnant, and only $0.78 \%$ being an unexpected pregnancy. This suggests that most women are unlikely to be pregnant on presentation and of those, half were unexpected, consistent with the studies mentioned. This finding suggests that a full sexual and pregnancy history, if taken, can potentially alleviate the need for any pregnancy testing in most patients. If a test is required, a urine $\beta$-HCG test may be sufficient. However, a blood $\beta$-HCG should be used in the setting of inability to gain a urine specimen in a reasonable timeframe and would require revision of the current policy.

The study also demonstrated that compliance with testing is problematic. Under two-thirds of patient's eligible for testing actually had a blood $\beta$-HCG completed on their blood panels, either in the ED or within 24 hours of admission to an in-patient ward. The reassuring aspect of these findings was that a majority of patients had blood tests sent for measurement $(99.3 \%, \mathrm{n}=2421)$. To increase compliance if the current policy continues, further education to the toxicology service staff to request or add orders onto patient blood samples would likely increase the rate more consistently than education to new members of the ED or Intensive Care Unit where patients mostly board after admission. If the policy is amended to incorporate clinical history and urine $\beta$-HCG testing, compliance may increase after appropriate education.

The study also demonstrated a trend towards single agent use in close to $60 \%$ of poisonings which present to ED, with this trend continuing on patients with unexpected pregnancy but reversed in those who had a positive blood $\beta$-HCG or pre-existing pregnancy. This could be related to overall intent in terms of the poisoning in women who are known to be pregnant, and whether they perceive this as a way to initiate an abortion or miscarriage. This potential outcome would need more studies to determine veracity over time but it is an interesting finding. Polypharmacy also occurred in 40-50\% of patients, which is consistent with previous studies which found this to occur in up to $37 \%$ and justified it by suggesting that there should be a high index of suspicion in pregnant women due to unique psychiatric considerations and social interventions may be indicated. ${ }^{11,18}$

Deliberate self-poisoning (DSP) was the most common method of self-harm and attempted suicide in this study, which was noted by a persistent trend in all study groups and is consistent with previous studies. ${ }^{19}$ With regard to the drugs ingested, paracetamol was involved in between $21 \%$ and $30 \%$ in all subgroups, consistent with Australian and international studies. ${ }^{24,25} \mathrm{We}$ also noted that there was significant use of opiates, benzodiazepines and recreational drugs 
which in terms of population toxicology are quickly becoming leading causes of poisonings in both Australia, the US and Europe.

Finally, a simple cost analysis was undertaken to determine the expenditure related to the practice of blood $\beta$-HCG being used to determine pregnancy, given that the prevalence of pregnancy in our population was so low. To screen poisoned women of childbearing years who are exposed to any drugs with the potential for toxicity, a blood quantitative $\beta$-HCG using the Medicare Benefits Schedule can be billed under item number 73,529 at $\$ 28.45$ per test for $100 \%$ of the benefit. In our cohort of 1605 patient tests, this would equate to $\$ 45,662.25$ of the health budget spent to identify the 19 unexpected pregnancies. If all patients who met inclusion criteria had been tested, this cost would have equated to $\$ 69,361.10$. The overall unintended cost to the health budget equates to $\$ 2403.28$ per identification of each unexpected pregnancy $(\mathrm{n}=19)$. With total compliance, 2438 tests rather than 1605 tests would have been performed and the expected cost per unexpected pregnancy found would equate to $\$ 2312.04(\mathrm{n}=30$, extrapolated from 800 tests finding 10 new unexpected pregnancies). In comparison, a urine $\beta$-HCG qualitative test under item number 73,527 can be billed at $\$ 10$ per test. If all patients were screened with urine the total cost would equate to $\$ 24,830(n=2483)$, which would lead to savings to the health budget but potentially at the expense of missing some unexpected pregnancies with potential false-negative tests. To reduce the rate of missing pregnancy and the potential costs of missed pregnancies in litigation, a blood $\beta$-HCG could be completed for those unable to give a urine test or if there were concerns over the potential for false-negative results due to other factors.

This study had some limitations. It was a retrospective observational study with no blinding. We also did not collect data on patients who had a full sexual and pregnancy history explored by the ED or toxicology doctor or those who received a urine $\beta$-HCG qualitative test. Therefore, the number of women actually tested for pregnancy may be greater. This mode of testing did not alleviate the need for a blood $\beta$-HCG test in our department policy due to previous cases of no $\beta$-HCG being completed when urine was unable to be collected.

\section{Conclusions}

Our study demonstrated low prevalence of pregnancy in women of childbearing age presenting with drug overdose, and an even lower rate of unexpected pregnancy. Deliberate self-poisoning was the main method of poisoning and paracetamol was the most commonly ingested drug in our population. Compliance with blood $\beta$-HCG testing was found to be completed in just under two-thirds of our patient population as determined by the departmental policy. Given the low prevalence, a change to urine $\beta$-HCG testing should be considered as first-line in ascertaining pregnancy status in our patient population and an amendment to the policy undertaken. In the event that a urine test cannot be obtained, a blood $\beta$-HCG test should be obtained. Given that most adverse fetal effects occur from pharmaceuticals rather than recreational substances, limiting $\beta$-HCG testing to DSP patients and those with therapeutic misadventure may increase compliance rates and limit the testing to this at-risk group.

\section{Abbreviations}

$\beta$-HCG, beta-human chorionic gonadotropin; DSP, deliberate self-poisoning; TM, therapeutic misadventure.

\section{Data Sharing Statement}

De-identified data will be made available on reasonable request to the corresponding author.

\section{Ethics Approval}

This study was approved as a Quality Assurance study by the Western Sydney Local Health District Human Research and Ethics Committee. Consent was waived due to the retrospective nature of the study. The privacy of patients was maintained through de-identification of data by the research team which provided anonymity.

\section{Author Contributions}

All authors made a significant contribution to the work reported including the conception, study design, acquisition of data, analysis and interpretation of the data and took part in drafting, revising and critically reviewing the article. All 
authors have also given final approval of the version to be published and agree to be accountable for all aspects of the work.

\section{Funding}

There were no internal or external funding sources for this study.

\section{Disclosure}

There are no financial or non-financial competing interests for this study.

\section{References}

1. Weiss HB. Pregnancy-associated injury hospitalizations in Pennsylvania, 1995. Ann Emerg Med. 1999;34:626-636. doi:10.1016/S0196-0644(99) 70165-4

2. Zelner I, Matlow J, Hutson JR, et al. Toxicology Investigators Consortium (ToxIC). Acute poisoning during pregnancy: observations from the toxicology investigators consortium. J Med Toxicol. 2015;11:301-308. doi:10.1007/s13181-015-0467-y

3. Flint C, Larsen H, Nielsen GL, Olsen J, Sørensen HT. Pregnancy outcome after suicide attempt by drug use: a Danish population-based study. Acta Obstet Gynecol Scand. 2002;81:516-522. doi:10.1034/j.1600-0412.2002.810607.x

4. Czeizel AE, Tímár L, Susánszky E. Timing of suicide attempts by self-poisoning during pregnancy and pregnancy outcomes. Int $J$ Gynaecol Obstet. 1999;65:39-45. doi:10.1016/S0020-7292(99)00007-7

5. Timmermann G, Acs N, Bánhidy F, Czeizel AE. A study of teratogenic and fetotoxic effects of large doses of meprobamate used for a suicide attempt by 42 pregnant women. Toxicol Ind Health. 2008;24:97-107. doi:10.1177/0748233708089015

6. Czeizel AE, Mosonyi A. Monitoring of early human fetal development in women exposed to large doses of chemicals. Environ Mol Mutagen. 1997;30:240-244. doi:10.1002/(SICI)1098-2280(1997)30:2<240::AID-EM17>3.0.CO;2-D

7. Petik D, Acs N, Bánhidy F, Czeizel AE. A study of the potential teratogenic effect of large doses of promethazine used for a suicide attempt by 32 pregnant women. Toxicol Ind Health. 2008;24:87-96. doi:10.1177/0748233708089003

8. Gidai J, Acs N, Bánhidy F, Czeizel AE. An evaluation of data for 10 children born to mothers who attempted suicide by taking large doses of alprazolam during pregnancy. Toxicol Ind Health. 2008;24:53-60. doi:10.1177/0748233708089017

9. McClure CK, Patrick TE, Katz KD, Kelsey SF, Weiss HB. Birth outcomes following self-inflicted poisoning during pregnancy. California, 2000 to 2004. J Obstet Gynecol Neonatal Nurs. 2011;40:292-301. doi:10.1111/j.1552-6909.2011.01250.x

10. Mosonyi A, Tímár L, Czeizel E. Timing of attempted suicide by drug poisoning during pregnancy and pregnancy outcome. Orv Hetil. 1997;138:2467-2470.

11. Perrone J, Hoffman RS. Toxic ingestions in pregnancy: abortifacient use in a case series of pregnant overdose patients. Acad Emerg Med. 1997;4:206-209. doi:10.1111/j.1553-2712.1997.tb03742.x

12. Czeizel AE, Gidai J, Petik D, Timmermann G, Puhó EH. Self-poisoning during pregnancy as a model for teratogenic risk estimation of drugs. Toxicol Ind Health. 2008;24:11-28. doi:10.1177/0748233708089020

13. Stengel CL, Seaberg DC, MacLeod BA. Pregnancy in the emergency department: risk factors and prevalence among all women. Ann Emerg Med. 1994;24:697-700. doi:10.1016/S0196-0644(94)70280-2

14. Goyal MK, Hersh AL, Badolato G, et al. Underuse of pregnancy testing for women prescribed teratogenic medications in the emergency department. Acad Emerg Med. 2015;22:192-196. doi:10.1111/acem.12578

15. De Santis M, Di Gianantonio E, Straface G, et al. Ionizing radiations in pregnancy and teratogenesis: a review of literature. Reprod Toxicol. 2005;20:323-329. doi:10.1016/j.reprotox.2005.04.004

16. Roberts SCM, Wingo E, Kimport K. A qualitative exploration of women's experiences discovering pregnancies in the emergency department. Contracept X. 2020;2:100024. doi:10.1016/j.conx.2020.100024

17. Bronstein AC, Spyker DA, Cantilena LR, et al. 2010 annual report of the American Association of Poison Control Centres National Poison Data System (NPDS): 28th Annual Report. Clin Toxicol. 2011;49:910-941. doi:10.3109/15563650.2011.635149

18. Rayburn W, Aronow R, DeLancey B, Hogan MJ. Drug overdose during pregnancy: an overview from a metropolitan poison control center. Obstet Gynecol. 1984;64:611-614.

19. Gandhi SG, Gilbert WM, McElvy SS, et al. Maternal and neonatal outcomes after attempted suicide. Obstet Gynecol. 2006;107:984-990. doi:10.1097/01.AOG.0000216000.50202.f6

20. Herskovits AZ, Chen Y, Latifi N, Ta RM, Kriegel G. False-negative urine human chorionic gonadotropin testing in the clinical laboratory. Lab Med. 2020;51:86-93. doi:10.1093/labmed/lmz039

21. Griffey RT, Trent CJ, Bavolek RA, Keeperman JB, Sampson C, Poirier RF. "Hook-like effect" causes false-negative point-of-care urine pregnancy testing in emergency patients. J Emerg Med. 2013;44:155-160. doi:10.1016/j.jemermed.2011.05.032

22. Greene DN, Schmidt RL, Kamer SM, Grenache DG, Hoke C, Lorey TS. Limitations in qualitative point of care hCG tests for detecting early pregnancy. Clin Chim Acta. 2013;415:317-321. doi:10.1016/j.cca.2012.10.053

23. Gronowski AM, Cervinski M, Stenman UH, Woodworth A, Ashby L, Scott M. False-negative results in point-of-care qualitative human chorionic gonadotropin (hCG) devices due to excess hCGbeta core fragment. Clin Chem. 2009;55:1389-1394. doi:10.1373/clinchem.2008.121210

24. Chiew AL, Fountain JS, Graudins A, Isbister GK, Reith D, Buckley NA. Summary statement: new guidelines for the management of paracetamol poisoning in Australia and New Zealand. Med J Aust. 2015;203:215-218. doi:10.5694/mja15.00614

25. Larson AM, Polson J, Fontana RJ, et al.; Acute Liver Failure Study Group. Acetaminophen-induced acute liver failure: results of a United States multicenter, prospective study. Hepatology. 2005;42:1364-1372. doi:10.1002/hep.20948 


\section{Publish your work in this journal}

Clinical Audit is an international, peer-reviewed, open access journal focusing on the processes and outcomes of clinical audit in any area of healthcare. All aspects of patient care are addressed within the journal and practitioners from all disciplines are invited to submit their work. Areas covered include: Publication of audits; How an audit has changed practice; Practical tips on how to do audits and to avoid pitfalls; How audits have changed patient care; Calls and justifications for new audits. The manuscript management system is completely online and includes a very quick and fair peer-review system, which is all easy to use. Visit http://www.dovepress.com/testimonials.php to read real quotes from published authors.

Submit your manuscript here: https://www.dovepress.com/clinical-audit-journal 